\title{
Electron Capture Dissociation Mass Spectrometry of Tyrosine Nitrated Peptides
}

\author{
Andrew W. Jones, ${ }^{a}$ Victor A. Mikhailov, ${ }^{\text {a }}$ Jesus Iniesta, ${ }^{\mathrm{b}}$ and \\ Helen J. Cooper ${ }^{\mathrm{a}}$ \\ ${ }^{a}$ School of Biosciences, University of Birmingham, Edgbaston, Birmingham, United Kingdom \\ ${ }^{b}$ Department of Physical Chemistry, University of Alicante, Alicante, Spain
}

\begin{abstract}
In vivo protein nitration is associated with many disease conditions that involve oxidative stress and inflammatory response. The modification involves addition of a nitro group at the position ortho to the phenol group of tyrosine to give 3-nitrotyrosine. To understand the mechanisms and consequences of protein nitration, it is necessary to develop methods for identification of nitrotyrosine-containing proteins and localization of the sites of modification. Here, we have investigated the electron capture dissociation (ECD) and collision-induced dissociation (CID) behavior of 3-nitrotyrosine-containing peptides. The presence of nitration did not affect the CID behavior of the peptides. For the doubly-charged peptides, addition of nitration severely inhibited the production of ECD sequence fragments. However, ECD of the triply-charged nitrated peptides resulted in some singly-charged sequence fragments. ECD of the nitrated peptides is characterized by multiple losses of small neutral species including hydroxyl radicals, water and ammonia. The origin of the neutral losses has been investigated by use of activated ion (AI) ECD. Loss of ammonia appears to be the result of non-covalent interactions between the nitro group and protonated lysine side-chains. (J Am Soc Mass Spectrom 2010, 21, 268-277) (c) 2010 American Society for Mass Spectrometry
\end{abstract}

$\mathrm{I}$ n many cases, post-translational modifications (PTMs) of proteins are fundamental for their correct function. In the case of protein tyrosine nitration, the modification can be considered a marker of nitrative stress [1]. Peroxynitrite $\left(\mathrm{ONOO}^{-}\right)$anions, formed in the reaction of superoxide radical anions and nitric oxide radicals, or other nitrating agents, e.g., $\mathrm{NO}_{2}{ }^{\bullet}$ radicals, react with tyrosine to produce the 3-nitrotyrosine modification [2-4]. The modification is of great interest as it may be used as a diagnostic biomarker for diseases caused by radical species [4-6]. Examples include cardiovascular disease [7], Alzheimer's disease [8], and atherothrombotic diseases [9]. The development of methods for the identification of tyrosine-nitrated proteins and characterization of sites of 3-nitrotyrosine are key for the understanding of the associated biological processes. Mass spectrometry approaches for the study of protein tyrosine nitration have been reviewed recently [1]. Most studies have utilized MALDI-TOF-MS, however electrospray tandem mass spectrometry (MS/MS) approaches employing collision-induced dissociation (CID) mass spectrometry have also been applied.

The introduction of electron capture dissociation (ECD) $[10,11]$ in 1998 provided a unique fragmentation technique for biomolecular analysis. ECD differs from "slow-heating" MS/MS techniques [12], such as collision-

Address reprint requests to Dr. H. J. Cooper, School of Biosciences, University of Birmingham, Edgbaston, Birmingham B15 2TT, UK. E-mail: H.J.Cooper@bham.ac.uk induced dissociation (CID) or infrared multi-photon dissociation (IRMPD) $[13,14]$. CID and IRMPD are thermal processes in which the lowest energy bonds are cleaved first [15]. The differences lead to different sets of fragmentation products being formed; ECD peptide backbone cleavage occurs at the $\mathrm{N}-\mathrm{C} \alpha$ bond, leading to $c$ and $z \bullet($ or $c \bullet$ and $z$ ) fragments [16, 17], whereas CID and IRMPD peptide backbone cleavage occurs at $\mathrm{N}-\mathrm{C}_{\mathrm{O}}$ bonds producing $b$ and $y$ ions [18].

In ECD, ions of interest are irradiated with lowenergy electrons $(<0.2 \mathrm{eV})$ producing charge-reduced species, which dissociate along radical-driven pathways, though the precise mechanism is still of some discussion [17, 19, 20]. In summary, initial electron capture to high- $n$ Rydberg states was first proposed by McLafferty and coworkers [10]. In the Cornell mechanism, the electron subsequently localizes to a site of protonation (e.g., lysine or arginine side-chain) forming a hypervalent radical. Hydrogen atom transfer to the amide oxygen occurs followed by cleavage of the adjacent $\mathrm{N}-\mathrm{C} \alpha$ bond. A limitation of the Cornell mechanism is the failure to explain the observation of ECD fragments for species in which mobile hydrogen atoms are absent [21]. In the Utah-Washington (UW) mechanism $[20,22]$, following capture the electron is localized to the amide $\pi^{*}$ orbital rendering the amide bond superbasic. The amide anion radical subsequently abstracts a proton from an accessible site. That process may involve a conformational change governed by 
Coulombic interactions between the amide anion and the site of protonation.

ECD offers some advantages over other MS/MS techniques for the analysis of peptides and proteins. For example, ECD is nonselective, the only exception being cleavage $N$-terminal to proline [23], and thus leads to greater peptide sequence coverage [24, 25]. Arguably the main benefit of ECD is the tendency of backbone fragments to retain labile posttranslational modifications [26], cf CID and IRMPD, where cleavage of the PTM is generally the dominant fragmentation channel. ECD has been shown to be successful for localizing sites of $\gamma$-carboxyglutamic acid [26], sulfation [26], $\mathrm{N}$ - and O-glycosylation [27, 28], phosphorylation [29, 30], acetylation [31], oxidation [32], ubiquitination [33], and sumoylation [34].

Although ECD has been applied to the characterization of a wide range of PTMs, the studies have not been exhaustive. Moreover, whilst ECD has generally been found to be successful in the analysis of PTMs, one cannot conclude this will always be the case. For example, interactions between phosphate groups and basic amino acid side-chains have been shown to have an adverse effect on the ECD fragmentation of phosphopeptides [35]. Beauchamp and coworkers have shown that the electron affinity (EA) of the species under investigation may also affect ECD behavior [36]. None of the unmodified proteinogenic amino acids have a positive electron affinity. However, it was shown that benzyl modifications of cysteine with an EA of $\geq 1.00 \mathrm{eV}$, specifically 3-nitrobenzylcysteine $(\mathrm{EA}=1.00 \mathrm{eV}$ [37] and 3,5-dinitrobenzylcysteine (EA $=1.65 \mathrm{eV}$ [38], termed 'electron predators', inhibit peptide backbone cleavage by ECD and the related electron-transfer dissociation (ETD) completely [36]. Identical rates of electron capture were observed for doubly-charged peptides containing modifications with disparate EA suggesting initial electron capture is governed by longrange interactions, i.e., the electron is captured to high- $n$ Rydberg states, as proposed by McLafferty [10]. Once captured, electron relaxation via through-space or through-bond transfer to the high-EA modification (electron predator) occurs in competition with transfer to the amide $\pi^{*}$ orbital (UW mechanism). The radical anions formed by the electron predator have high proton affinities thus enabling proton transfer from a site of protonation. The result is a stable radical intermediate, which does not undergo $\mathrm{N}-\mathrm{C} \alpha$ cleavage to produce $c / z$ ions. It was suggested that 3-nitrotyrosinecontaining peptides may also behave as electron predators due to the structural similarity of nitrotyrosine and nitrobenzylcysteine [36].

In this work, we investigate the effect of 3-nitrotyrosine on the electron capture dissociation behavior of peptides. The ECD and CID of the synthetic peptides GPLEnYGFAK, GPLEnYGFAKGPLAK, the synthetic fibrinogen $\beta$-chain peptide NYCGLPGEnYWLGNDK (known to be susceptible to tyrosine nitration at this site in vivo [9]), the myoglobin tryptic peptide
nYLEFISDAIIHVLHSK (nY denotes 3-nitrotyrosine), and their unmodified counterparts were determined. The results show that for doubly-charged peptide ions the presence of 3-nitrotyrosine has a deleterious effect on ECD backbone cleavage. The ECD mass spectra reveal abundant neutral losses from the charge-reduced precursor. The origin of these neutral losses was investigated by use of activated ion (AI) ECD [39], with further insight provided by ECD of an isotopically labeled ${ }^{15} \mathrm{NO}_{2}$-tyrosine-containing peptide, and a peptide series with variable sites of nitrotyrosine $\left(\mathrm{A}_{\mathrm{x}} \mathrm{nYA} \mathrm{A}_{\mathrm{y}} \mathrm{K}\right.$, where $\mathrm{x}, \mathrm{y}=0-6$ and $(\mathrm{x}+\mathrm{y})=$ 6). For triply-charged peptides, in addition to the abundant neutral losses, some ECD backbone cleavage is observed. That observation is discussed in terms of competing electron relaxation processes.

\section{Experimental}

\section{Preparation of Synthetic Peptides}

The nitrated peptides, GPLEnYGFAK, GPLEnYGFAKGPLAK, and NYCGLPGEnYWLGNDK (a fibrinogen $\beta$-chain tryptic peptide), their unmodified counterparts and an $\mathrm{A}_{\mathrm{x}} \mathrm{nYA} \mathrm{A}_{\mathrm{y}} \mathrm{K}$ series (where $\mathrm{x}, \mathrm{y}=0-6$, and $\mathrm{x}+\mathrm{y}=$ 6) were synthesized by Alta Bioscience (Birmingham, UK) and used without further purification. The peptides were diluted to $2 \mathrm{pmol} / \mu \mathrm{L}$ in methanol (Fisher Scientific, Leicestershire, UK):water (J.T. Baker, Deventer, The Netherlands) (50:50), and 1\% formic acid (Fisher Scientific).

Equine skeletal myoglobin (Sigma-Aldrich, Poole, Dorset, UK) was electrochemically nitrated in a watercooled cell at $284 \pm 2 \mathrm{~K}$, with the potential fixed at 1.05 $\mathrm{V}$ versus $\mathrm{Ag} / \mathrm{AgCl} / \mathrm{Cl}^{-}(3 \mathrm{M})$ using an Amel Instruments 2053 potentiostat (Milan, Italy). The cathodic compartment was a $5 \mathrm{~mm}$ diameter cylindrical chamber separated from the anodic compartment by a nonselective sintered glass membrane. A platinum wire from Goodfellow (0.5 mm diameter, $+99.995 \%$ purity) was used as the counter electrode. The cathodic compartment was filled with $1 \mathrm{~mL}$ of buffer solution comprising $50 \mathrm{mM} \mathrm{Na}{ }_{2} \mathrm{~B}_{4} \mathrm{O}_{7} \cdot 10 \mathrm{H}_{2} \mathrm{O}$ and $50 \mathrm{mM} \mathrm{NaNO}$ adjusted to $\mathrm{pH} 9.0$ with $\mathrm{H}_{3} \mathrm{BO}_{3}$. A $0.1 \times 2.5 \times 5.0 \mathrm{~cm}$ bipolar boron-doped diamond working electrode was pretreated by cycling the electrode between 0 and $4 \mathrm{~V}$ versus $\mathrm{Ag} / \mathrm{AgCl}, 0.1 \mathrm{~V} \mathrm{~s}^{-1}, 10$ cycles, in $1 \mathrm{M}$ nitric acid, and thereafter electrodes were thoroughly rinsed with ultrapure water. Buffer solution $(50 \mathrm{~mL})$ contained $1 \mathrm{mg}$ $\mathrm{mL}^{-1}$ of protein. Sodium nitrite concentration was 50 $\mathrm{mM}$. Electrosynthetic nitration was monitored with a Digatron electronic A.h coulometer (Aachen, Germany) by measuring the charge passed through the circuit. The nitration was expected to take place at Tyr103 [40]. The reaction mixture was extensively dialyzed against $10 \mathrm{mM}$ ammonium acetate, $\mathrm{pH}$ 6.0, using Spectra/Por (Rancho Dominguez, CA, USA) molecular porous membrane tubing with $3500 \mathrm{Da}$ cut-off. Samples were subsequently freeze-dried and stored at $-20^{\circ} \mathrm{C}$. Nitrated myoglobin was digested with trypsin (Trypsin 
Gold; Promega, Madison, WI, USA) (1:20, enzyme to protein, wt/wt) in $50 \mathrm{mM}$ ammonium bicarbonate (Fisher Scientific) (pH 8) at $37{ }^{\circ} \mathrm{C}$ overnight. Digestion was quenched with formic acid $(0.5 \% \mathrm{vol} / \mathrm{vol})$ and the peptides were desalted using a Michrom $\mathrm{C}_{18}$ Macrotrap (200 $\mu \mathrm{g}$ capacity). The digest was diluted to a final concentration of $\sim 2 \mathrm{pmol} / \mu \mathrm{L}$ in methanol:water (50:50) and $1 \%$ formic acid.

${ }^{15} \mathrm{~N}$-isotopicnitrotyrosinelabeling ofGPLEYGFAKGPLAK was completed by the electrochemical procedure described above, with the exception that $>98 \%{ }^{15} \mathrm{~N}$ labeled sodium nitrate (Sigma-Aldrich, Poole, Dorset, UK) was used.

\section{Mass Spectrometry}

All tandem mass spectrometry analyses were performed on a Thermo Finnigan LTQ FT mass spectrometer (Thermo Fisher Scientific, Bremen, Germany). Samples were injected by use of an Advion Biosciences Triversa electrospray source (Advion Biosciences, Ithaca, $\mathrm{NY}, \mathrm{USA}$ ) at a flow rate of $\sim 200 \mathrm{~nL} / \mathrm{min}$.

All MS/MS spectra were acquired in the ICR cell with a resolution of 100000 at $m / z 400$.

ECD. Precursor ions were isolated in the linear ion trap and transferred to the ICR cell for ECD. Automatic gain control (AGC) target was $5 \times 10^{5}$ with maximum fill time 2 s. Isolation width was $5 \mathrm{~m} / \mathrm{z}$. Electrons for ECD were produced by an indirectly heated bariumtungsten cylindrical dispenser cathode (5.1 mm diameter, $154 \mathrm{~mm}$ from the cell, $1 \mathrm{~mm}$ off axis) (Heat-Wave Labs, Watsonville, CA, USA). The current across the electrode was $\sim 1.1 \mathrm{~A}$. Ions were irradiated with electrons for $70 \mathrm{~ms}$ at 5\% energy (corresponding to a cathode potential of $-2.775 \mathrm{~V}$ ). Each ECD scan comprises 4 co-added microscans. Mass spectra shown comprise 100 averaged scans.

Activated ion (AI) ECD. Photons for infrared irradiation were provided by a $75 \mathrm{~W}$ in-built $\mathrm{CO}_{2}$ laser (Synrad, Mikilteco, WA, USA) for $100 \mathrm{~ms}$ and measured as percent of the maximum (i.e., $75 \mathrm{~W}$ ). Infrared irradiation was followed by ECD with an $85 \mathrm{~ms}$ delay [41]. Thirty AI ECD scans were recorded at laser powers ranging from 0 to $50 \%$ etc. Each AI ECD scan comprised 10 co-added microscans. Experiment was completed in triplicate.

CID. CID experiments were performed in the linear ion trap and the fragments transferred to the ICR cell for detection. AGC target was $1 \times 10^{6}$, maximum fill time $1 \mathrm{~s}$. Isolation width was $5 \mathrm{~m} / \mathrm{z}$. CID experiments were performed with helium gas at normalized collision energy $35 \%$. Each CID scan comprises four coadded microscans. Mass spectra shown comprise 100 averaged scans.

Data were analyzed using Xcalibur 2.05 software (Thermo Fisher Scientific). All mass spectra were manually searched for $a, b, c \bullet / c, y$, and $z \bullet / z$ fragment ions using Protein Prospector ver. 5.2.2 software (UCSF, San Francisco, CA, USA) [42].

\section{Results and Discussion}

Figure 1 shows the mass spectra obtained following CID and ECD of the doubly-charged peptide ions. With the exception of the myoglobin peptide, ECD resulted in virtually complete sequence coverage (Figure 1, left-hand column) of the unmodified peptides. For the unmodified myoglobin peptide, four of the fifteen $\mathrm{N}-\mathrm{C} \alpha$ bonds were cleaved. The addition of nitration on the tyrosine on the peptide drastically decreases the ECD sequence coverage in all cases (Figure 1, middle column). A striking feature of the ECD mass spectra obtained from the nitrated peptides is the presence of intense peaks corresponding to neutral losses from the charge-reduced $[\mathrm{M}+2 \mathrm{H}]^{+}$species. The neutral losses observed are summarized in Table 1 . All nitrated peptides exhibited multiple neutral losses following electron capture, and in all cases the abundance of at least one of these fragment ions is greater than the abundance of the charge-reduced ions. The abundances of the peaks corresponding to neutral losses appear to be peptide dependent. For example, the most abundant product following ECD of [GPLEnYGFAK $+2 \mathrm{H}]^{2+}$ ions was loss of $\left[\bullet \mathrm{OH}+\mathrm{H}_{2} \mathrm{O}+\mathrm{NH}_{3}\right]$, whereas for [GPLEnYGFAKGPLAK $+2 \mathrm{H}]^{2+}$ ions it was $\left[\mathrm{H}_{2} \mathrm{O}+\right.$ $\mathrm{NH}_{3}$ ]. The addition of nitration did not affect CID behavior for these peptides. Extensive sequence coverage was observed for both unmodified peptides (data not shown), and modified peptides (Figure 1, right-hand column).

ECD MS/MS of the triply-charged peptides $[\text { GPLEnYGFAK }+3 \mathrm{H}]^{3+}$ and [nYLEFISDAIIHVLHSK + $3 \mathrm{H}]^{3+}$ are shown in Figure 2. Addition of a third proton to the nitrated peptides leads to improved sequence coverage with four extra $c$ and $z$ ions being identified for GPLEnYGFAKGPLAK, and eight more $c$ and $z$ ions being noted for nYLEFISDAIIHVLHSK. As with the doubly-charged peptides, intense peaks corresponding to neutral losses from the charge-reduced species are observed (see Table 1).

Nitration of tyrosine severely inhibits $\mathrm{N}-\mathrm{C} \alpha$ backbone cleavage following electron capture by doublycharged peptide ions. That result can be explained in terms of the 'electron predator' model proposed by Sohn et al. [36]: following electron capture to high- $n$ Rydberg states, through-space or through-bond electrontransfer occurs to the 3-nitrotyrosine, rather than the $\pi^{*}$ orbital associated with $c / z$-type cleavage (UW mechanism). The 3-nitrotyrosine anion radical then abstracts a proton from elsewhere in the peptide thus halting the normal sequence of events. Based on the proton affinities of the amino acid side-chains and N-terminus, and charge-repulsion factors, the doubly-charged peptides studied here are predicted to be protonated at the $\mathrm{N}$-terminus and on the side-chain of the C-terminal 
(a)

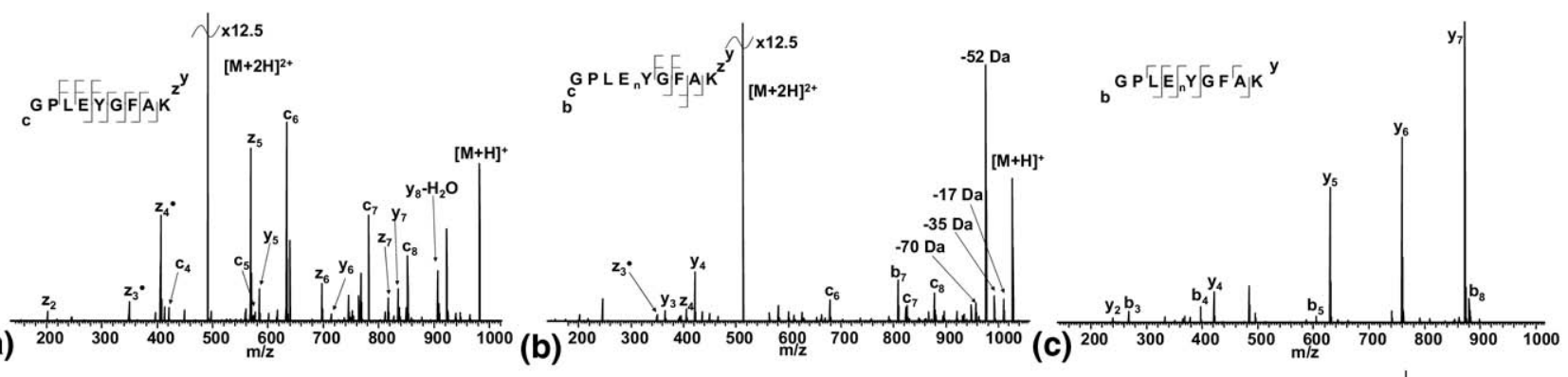

(d)
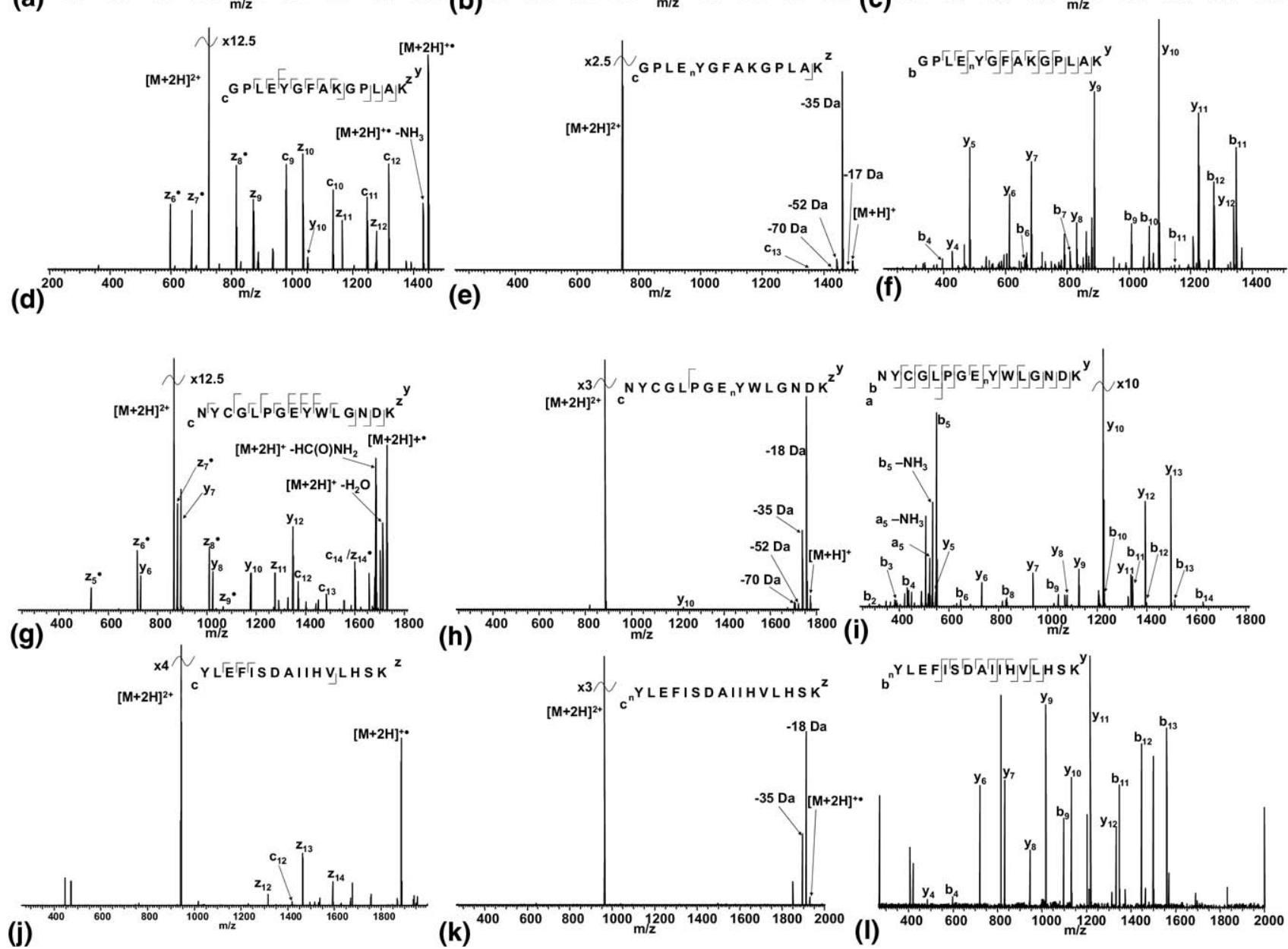

(e)

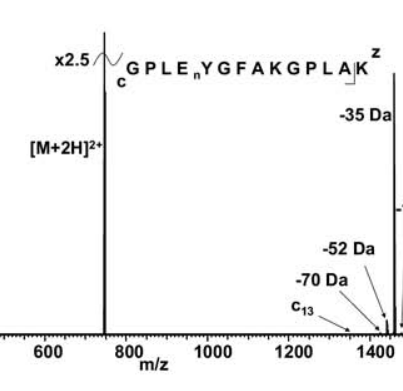

(f)

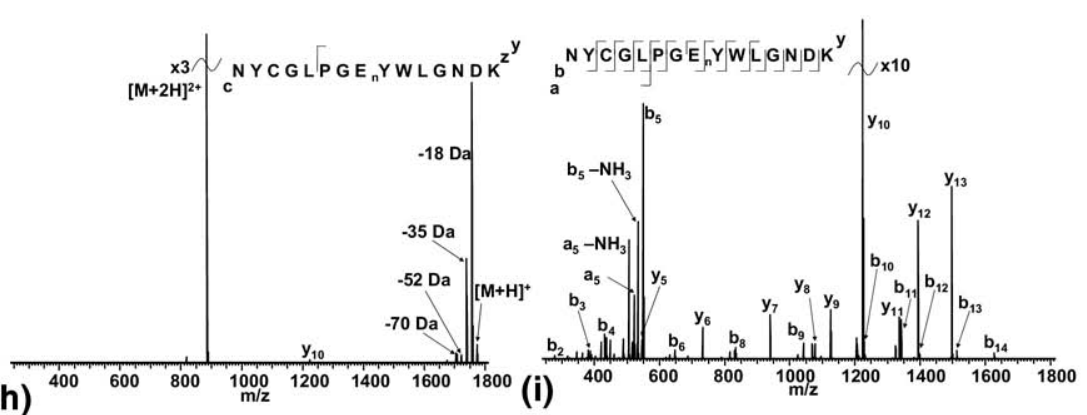

(h)
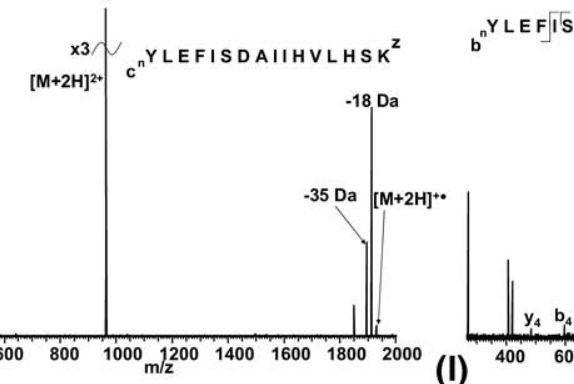

(k)

(I)

Figure 1. MS/MS spectra of doubly-charged peptides: (a) ECD of [GPLEYGFAK $+2 \mathrm{H}]^{2+}$ ions; (b) ECD of [GPLEnYGFAK $+2 \mathrm{H}]^{2+}$ ions; (c) CID of [GPLEnYGFAK $\left.+2 \mathrm{H}\right]^{2+}$ ions; (d) ECD of [GPLEYGFAKGPLAK $+2 \mathrm{H}]^{2+}$ ions; (e) ECD of [GPLEnYGFAKGPLAK $\left.+2 \mathrm{H}\right]^{2+}$ ions; (f) CID of $[\text { GPLEnYGFAKGPLAK }+2 \mathrm{H}]^{2+}$ ions; (g) ECD of [NYCGLPGEYWLGNDK $\left.+2 \mathrm{H}\right]^{2+}$ ions; (h) ECD of [NYCGLPGEnYWLGNDK $+2 \mathrm{H}]^{2+}$ ions; (i) CID of [NYCGLPGEnYWLGNDK $\left.+2 \mathrm{H}\right]^{2+}$ ions; (j) ECD of [YLEFISDAIIHVLHSK $+2 \mathrm{H}]^{2+}$ ions; $(\mathbf{k})$ ECD of [nYLEFISDAIIHVLHSK $\left.+2 \mathrm{H}\right]^{2+}$ ions; (l) CID of [nYLEFISDAIIHVLHSK $+2 \mathrm{H}]^{2+}$ ions. $\mathrm{nY}$ denotes 3-nitrotyrosine.

lysine residue. Proton transfer may occur from one of these sites or, alternatively, may be the result of proton abstraction from the adjacent phenol group to which it is hydrogen bonded (see below). An alternative explanation is that $c / z$-type cleavage does occur but there is no charge repulsion to overcome any intramolecular hydrogen bonds between the resulting fragments (one neutral, one singly-charged). Activated ion (AI) ECD experiments (discussed below) suggest the latter explanation is not the case.

\section{Loss of Neutrals Observed Following ECD of Nitrated Peptides}

As mentioned above, all of the nitrated peptides studied showed extensive loss of small neutrals from the charge-reduced species following electron capture. In all cases, at least one of these peaks was more abundant than that of the charge-reduced species. Figure 3 shows expanded $\mathrm{m} / \mathrm{z}$ regions of the ECD mass spectra containing peaks due to these losses. See also Table 1. Loss of 
Table 1. Summary of neutral losses observed for each peptide and charge state. Assignments are given together with experimental $\mathrm{m} / \mathrm{z}$ values $\left(\mathrm{m} / \mathrm{z}_{\text {meas }}\right)$ of the peaks and mass shifts $(\Delta \mathrm{m})$ from the charge-reduced $[\mathrm{M}+2 \mathrm{H}]^{+} \bullet$ or $[\mathrm{M}+3 \mathrm{H}]^{2+\bullet}$ ions

\begin{tabular}{|c|c|c|c|c|}
\hline \multirow[b]{2}{*}{ Peptide precursor ion } & \multicolumn{4}{|c|}{ Neutral losses observed } \\
\hline & $\begin{array}{c}\text { Assignment } \\
m / z_{\text {meas }} \Delta \mathrm{m}(\mathrm{Da})\end{array}$ & $\begin{array}{c}\text { Assignment } \\
m / z_{\text {meas }} \Delta \mathrm{m}(\mathrm{Da})\end{array}$ & $\begin{array}{c}\text { Assignment } \\
m / z_{\text {meas }} \Delta \mathrm{m}(\mathrm{Da})\end{array}$ & $\begin{array}{c}\text { Assignment } \\
m / z_{\text {meas }} \Delta \mathrm{m}(\mathrm{Da})\end{array}$ \\
\hline \multirow{3}{*}[\text{GPLEnYGFAK}+2\mathrm{H}]{$^{2+}$} & $\bullet \mathrm{OH}$ & $\bullet \mathrm{OH}, \mathrm{H}_{2} \mathrm{O}$ & $\bullet \mathrm{OH}, \mathrm{H}_{2} \mathrm{O}, \mathrm{NH}_{3}$ & $\bullet \mathrm{OH}, \mathrm{H}_{2} \mathrm{O}, \mathrm{NH}_{3}, \mathrm{H}_{2} \mathrm{O}$ \\
\hline & 1010.4988 & 992.4878 & 975.4618 & 957.4507 \\
\hline & 16.9984 & 35.0094 & 52.0354 & 70.0465 \\
\hline \multirow{3}{*}[\text{GPLEnYGFAKGPLAK}+2\mathrm{H}]{$^{2+}$} & $\bullet \mathrm{OH}$ & $\mathrm{H}_{2} \mathrm{O}, \mathrm{NH}_{3}$ & $\bullet \mathrm{OH}, \mathrm{H}_{2} \mathrm{O}, \mathrm{NH}_{3}$ & - $\mathrm{OH}, \mathrm{H}_{2} \mathrm{O}, \mathrm{NH}_{3}, \mathrm{H}_{2} \mathrm{O}$ \\
\hline & 1476.7963 & 1458.7590 & 1441.7562 & 1423.7293 \\
\hline & 16.9971 & 35.0344 & 52.0372 & 70.0641 \\
\hline \multirow{3}{*}{ 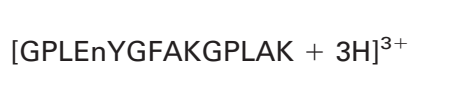 } & $\bullet \mathrm{OH}$ & $\mathrm{H}_{2} \mathrm{O}, \mathrm{NH}_{3}$ & $\bullet \mathrm{OH}, \mathrm{H}_{2} \mathrm{O}, \mathrm{NH}_{3}$ & \\
\hline & 738.8972 & 729.8806 & 721.3785 & \\
\hline & 16.9986 & 35.0318 & 52.0360 & \\
\hline \multirow{4}{*}[\text{NYCGLPGEnYWLGNDK}+2\mathrm{H}]{$^{2+}$} & $\mathrm{H}_{2} \mathrm{O}$ & $\bullet \mathrm{OH}, \mathrm{H}_{2} \mathrm{O}$ & $\bullet \mathrm{OH}, \mathrm{H}_{2} \mathrm{O}, \mathrm{NH}_{3}$ & $\bullet \mathrm{OH}, \mathrm{H}_{2} \mathrm{O}, \mathrm{NH}_{3}, \mathrm{H}_{2} \mathrm{O}$ \\
\hline & 1756.7663 & 1739.7595 & 1772.7254 & 1704.7013 \\
\hline & 18.0063 & 35.0131 & 52.0361 & 70.0713 \\
\hline & $\bullet \mathrm{OH}$ & $\mathrm{H}_{2} \mathrm{O}$ & $\bullet \mathrm{OH}, \mathrm{H}_{2} \mathrm{O}$ & $\mathrm{H}_{2} \mathrm{O}, \mathrm{H}_{2} \mathrm{O}$ \\
\hline \multirow[t]{2}{*}{ [nYLEFISDAIIHVLHSK $+2 \mathrm{H}]^{2+}$} & 1914.0190 & 1913.0167 & 1896.0096 & 1895.0059 \\
\hline & 17.0042 & 17.9980 & 35.0051 & 36.0088 \\
\hline \multirow{3}{*}[\mathrm{nYLEFISDAIIHVLHSK}+3\mathrm{H}]{$^{3+}$} & $\bullet \mathrm{OH}$ & $\bullet \mathrm{OH}, \mathrm{H}_{2} \mathrm{O}$ & $\mathrm{H}_{2} \mathrm{O}, \mathrm{H}_{2} \mathrm{O}$ & \\
\hline & 957.5086 & 948.5045 & 948.0017 & \\
\hline & 17.0030 & 35.0135 & 36.0191 & \\
\hline
\end{tabular}

Calculated mass shifts for $\bullet \mathrm{OH}, \mathrm{H}_{2} \mathrm{O}$ and $\mathrm{NH}_{3}$ are $17.0027 \mathrm{Da}$, 18.0106 Da, and 17.0265 Da, respectively.

a hydrogen atom from the charge-reduced species is observed for all nitrated peptides. That product is commonly observed in ECD mass spectra of peptides

(a)

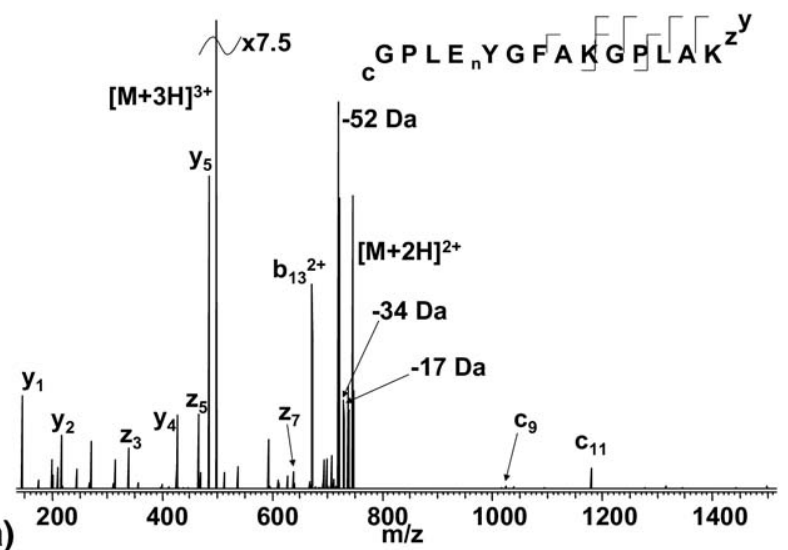

(b)

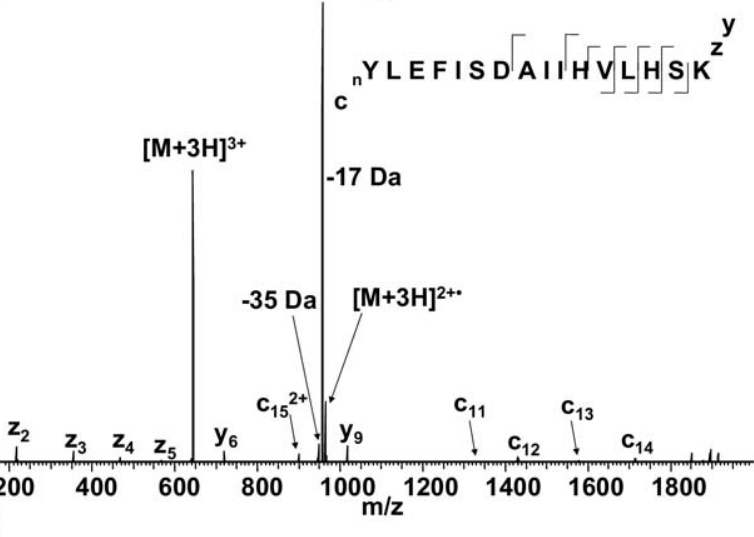

Figure 2. ECD mass spectra of triply-charged peptides: (a) $[\text { GPLEnYGFAKGPLAK }+3 \mathrm{H}]^{3+}$; (b) [nYLEFISDAIIHVLHSK $\left.+3 \mathrm{H}\right]^{3+}$. nY denotes 3-nitrotyrosine.
[43] and is indeed noted for unmodified GPLEYGFAK (Figure 1a). Given that events following electron capture appear to be different to those for 'standard' peptides, it cannot be concluded that hydrogen atom loss proceeds as in 'standard' peptides. Losses of hydroxyl radicals, water and ammonia are also observed.

Polášek and Tureček [44] have shown that the phenylnitronic radical is stable on the microsecond scale and undergoes unimolecular dissociation via hydroxyl loss. Sohn et al. [36] observed hydroxyl loss following ECD of doubly-charged peptides containing 3-nitrobenzylcysteine and 3,5-dinitrobenzylcysteine. They concluded that formation of the nitrobenzyl radical anion was followed by intramolecular proton transfer and subsequent homolytic cleavage of the $\mathrm{N}-\mathrm{OH}$ bond. They also noted that loss of $\bullet \mathrm{OH}$ was especially prominent with higher levels of vibrational excitation, i.e., in activated ion ECD and ETD with supplemental activation. Loss of $\bullet \mathrm{OH}$ is observed for all of the 3-nitrotyrosine containing peptides studied here, although this channel is very weak for [GPLEnYGFAKGPLAK + $2 \mathrm{H}]^{2+}$ precursor ions. We conclude that a similar process occurs, i.e., the nitrotyrosine radical anion is formed on electron capture and is followed by intramolecular proton transfer. The proton may be transferred from a lysine side-chain, however it is worth noting that addition of a nitro-group to tyrosine increases the acidity of the phenolic hydrogen $\left(\mathrm{pK}_{\mathrm{a}} 7.2\right.$ [45]. At acidic $\mathrm{pH}$ the hydroxyl group remains uncharged but is involved in hydrogen bonding to the neighboring nitration modification [46]. Hence possibly proton transfer from the phenol group occurs.

Analysis of isotopic distributions in the ECD mass spectrum of [NYCGLPGEnYWLGNDK $+2 \mathrm{H}]^{2+}$ pep- 


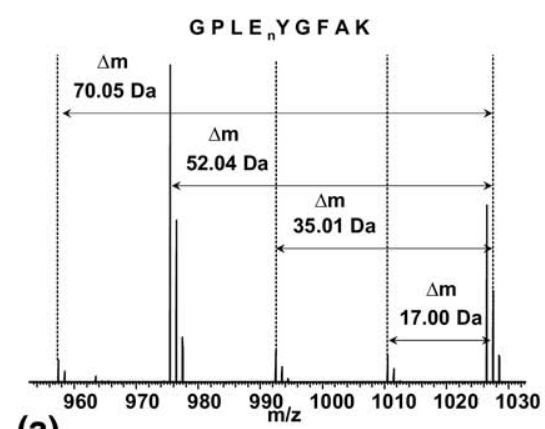

(a)

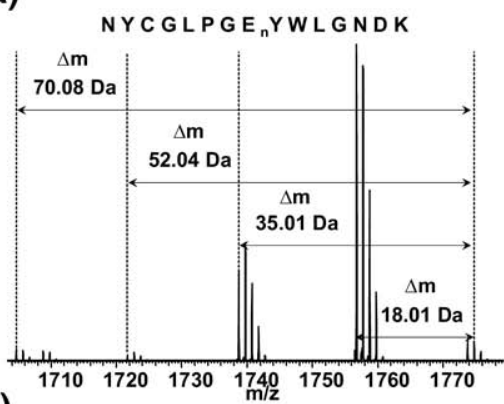

(d)

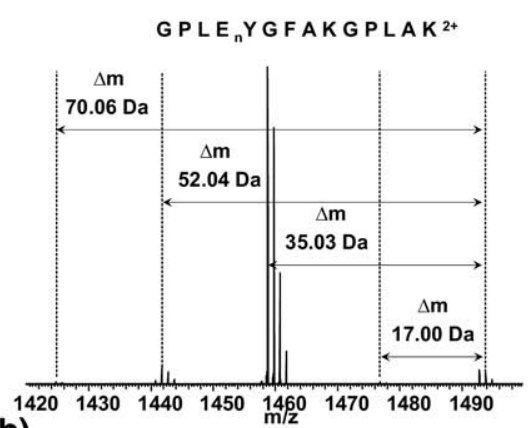

(b)

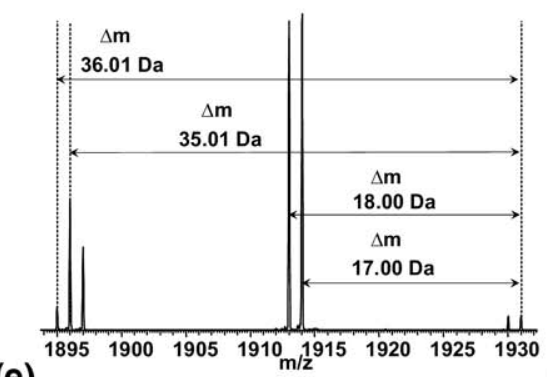

(c)
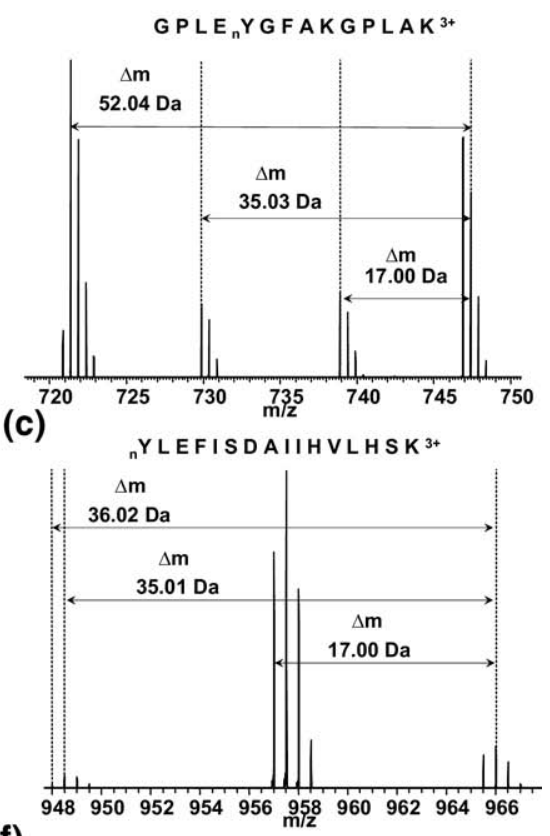

(e)

(f)

Figure 3. Expanded $m / z$ regions of ECD mass spectra showing peaks corresponding to neutral losses from the charge-reduced cation radical for precursor ions: (a) [GPLEnYGFAK $+2 \mathrm{H}]^{2+}$, (b) $[\text { GPLEnYGFAKGPLAK }+2 \mathrm{H}]^{2+}$, (c) [GPLEnYGFAKGPLAK $\left.+3 \mathrm{H}\right]^{3+}$, (d) [NYCGLPGEnYWLGNDK + $2 \mathrm{H}]^{2+}$, (e) $[\mathrm{nYLEFISDAIIHVLHSK}+2 \mathrm{H}]^{2+}$, and (f) [nYLEFISDAIIHVLHSK $\left.+3 \mathrm{H}\right]^{3+}$. Mass shifts $(\Delta \mathrm{m})$ from the mass of the charge-reduced $[\mathrm{M}+2 \mathrm{H}]^{+} \cdot$ and $[\mathrm{M}+3 \mathrm{H}]^{2+} \cdot$ ions for doubly- charged and triply-charged precursor ions, respectively, are indicated.

tide ions shows that loss of water rather than $\bullet \mathrm{OH}$ occurs. However, possibly the $[\mathrm{M}+2 \mathrm{H}]^{+\bullet}-18$ peak corresponds to loss of $\bullet \mathrm{OH}$ plus loss of $\bullet \mathrm{H}$. Similar analysis of the ECD mass spectrum of [nYLEFISDAIIHVLHSK + $2 \mathrm{H}]^{2+}$ ions (Figure 3e) shows the presence of both [M + $\mathrm{H}]^{+}$and $[\mathrm{M}+2 \mathrm{H}]^{+}$ions and peaks corresponding to the loss of $17.004 \mathrm{Da}$ from both. The neutral loss peaks have the same ratio of abundances as the $[\mathrm{M}+\mathrm{H}]^{+\bullet}$ and $[\mathrm{M}+2 \mathrm{H}]^{+\bullet}$ peaks, suggesting that the loss of $\bullet \mathrm{OH}$ occurs both from $[\mathrm{M}+\mathrm{H}]^{+}$and $[\mathrm{M}+2 \mathrm{H}]^{+\bullet}$ in this case.

Water loss after $\bullet \mathrm{OH}$ loss is observed for all peptides except GPLEnYGFAKGPLAK, where the combined loss of $\left[\mathrm{H}_{2} \mathrm{O}+\mathrm{NH}_{3}\right]$ is observed. Possibly, the water loss is related to hydrogen bonding of the phenol group to the nitro-group, however this might suggest additional loss of $\bullet \mathrm{OH}$, which we do not observe. Sohn et al. [36] observed additional water loss in the AI ECD and ETD with supplemental activation of the nitrobenzylcysteinecontaining peptides, but following ECD this additional water loss was not noted. That suggests that water loss is associated with higher vibrational excitation, and it may be that the precursor ions in our experiments are 'hotter' than those in Beauchamp's. Further indication of higher internal energy of the precursor ions in these experiments is the extensive hydrogen atom loss observed following ECD. Such losses were only observed following AI ECD in the experiments of Beauchamp and coworkers.

In addition to losses of $\bullet \mathrm{OH}$ and water, we observed losses of ammonia from the charge-reduced precursors.
Losses of ammonia are not uncommon following ECD of peptides, for example, see Figure 1d; however the abundances of the fragments involving ammonia loss from the nitrated peptides are remarkable. Moreover losses of ammonia did not occur in isolation but always occurred together with losses of other neutral species, Figure $3 a-d$, Table 1. For peptides GPLEnYGFAK and GPLEnYGFAKGPLAK the neutral losses involving ammonia produced the most abundant ECD product. For doubly-charged GPLEnYGFAK precursors, the most abundant product of ECD corresponds to loss of $\left[\bullet \mathrm{OH}+\mathrm{H}_{2} \mathrm{O}+\right.$ $\mathrm{NH}_{3}$ ]. For doubly-charged GPLEnYGFAKGPLAK precursors, it is loss of $\left[\mathrm{H}_{2} \mathrm{O}+\mathrm{NH}_{3}\right]$, and for triplycharged precursors it is $\left[\bullet \mathrm{OH}+\mathrm{H}_{2} \mathrm{O}+\mathrm{NH}_{3}\right]$. For [NYCGLPGEnYWLGNDK $+2 \mathrm{H}]^{2+}$ ions, loss of $\left[\bullet \mathrm{OH}+\mathrm{H}_{2} \mathrm{O}+\mathrm{NH}_{3}\right]$ is a minor product. No losses involving ammonia were observed for either $2+$ or $3+$ ions of nYLEFISDAIIHVLHSK, nor were any neutral losses involving ammonia observed following ECD of the nitrobenzylcysteine containing peptides studied by Beauchamp and coworkers [36]. As mentioned, ammonia loss was not observed in isolation in ECD of any of the nitrated peptides, but followed an initial loss of - $\mathrm{OH}$ or $\mathrm{H}_{2} \mathrm{O}$. Apparently the ammonia loss is intrinsically linked with the nitrotyrosine radical anion formed following electron capture although the mechanism is unclear. ${ }^{15} \mathrm{~N}$-isotopic labeling of the nitro- group reveals that it is not the origin of the ammonia nitrogen (see Supplemental Figure 1, which can be found in the electronic version of this article). Presumably, the am- 
monia is lost from a protonated lysine side-chain which is interacting with the nitro-group. As described above, for the doubly-charged peptides studied, the predicted protonation sites are the $\mathrm{N}$-terminus and the C-terminal lysine side-chain. For triply-charged GPLEnYGFAKGPLAK, the additional protonation site is predicted to be the sidechain of the central lysine, and for 3+ ions of nYLEFISDAIIIHVLHSK the side-chain of one of the histidine residues. The results for peptide nYLEFISDAIIHVLHSK suggest that the lysine side-chain is too distant from the nitro-group to initiate ammonia loss. Similarly, peptide NYCGLPGEnYWLGNDK shows only weak ammonia loss. The most abundant ECD product of both $[\text { GPLEnYGFAK }+2 \mathrm{H}]^{2+}$ ions and [GPLEnYGFAKGPLAK + $3 \mathrm{H}]^{3+}$ is loss of $\left[\bullet \mathrm{OH}+\mathrm{H}_{2} \mathrm{O}+\mathrm{NH}_{3}\right]$. Both of these species are expected to be protonated on Lys9 which we hypothesize is involved in noncovalent bonding with the nitro-group. If this is the case, we would expect the relative abundance of these peaks to decrease if the precursor ions are activated before ECD such that unfolding is induced. AI ECD was performed on these species and the results are presented in Figure 4a and c. The near-threshold AI ECD mass spectra are shown in Figure $4 \mathrm{~b}$ and $\mathrm{d}$. Infrared irradiation was followed by ECD with an $85 \mathrm{~ms}$ delay to ensure that ECD was performed on unfolded ions [41]. As can be seen, there is a rapid decrease in the relative abundance of the $\left[\bullet \mathrm{OH}+\mathrm{H}_{2} \mathrm{O}+\mathrm{NH}_{3}\right]$ neutral loss peaks with increasing pre-ECD activation. A less pronounced decrease in relative abundance is also noted for the other observed neutral loss peaks. The AI ECD results for doublycharged GPLEnYGFAKGPLAK are shown in Figure 4e and $f$ and are less straightforward to interpret. The peak corresponding to loss of $\left[\mathrm{H}_{2} \mathrm{O}+\mathrm{NH}_{3}\right]$ rapidly decreases in abundance, however this is accompanied by an increase in the abundance of the peaks corresponding to $\left[\bullet \mathrm{OH}+\mathrm{H}_{2} \mathrm{O}+\mathrm{NH}_{3}\right],\left[\bullet \mathrm{OH}+\mathrm{H}_{2} \mathrm{O}+\mathrm{NH}_{3}+\right.$ $\left.\mathrm{H}_{2} \mathrm{O}\right]$ and $[\bullet \mathrm{OH}]$ up to $\sim 30 \%$ laser power, followed by a general decrease which coincides with the onset of IRMPD. This result suggests IR activation promotes loss of $\bullet \mathrm{OH}$, however it should be noted that the fragment is a combination of neutral losses which cannot be deconvoluted with certainty. Beauchamp and coworkers [36] also observed increased loss of $\bullet \mathrm{OH}$ at higher vibrational energy levels. The contradiction in our findings may indicate differences in the mechanisms of - $\mathrm{OH}$ loss in the various peptide ion structures. It should also be noted that the variations in abundance of the neutral loss peaks with ion activation may reflect competitive dissociation channels and their dependence on ion internal energies rather than simply being the result of interruption of a particular fragmentation channel (i.e., loss of ammonia) by removal of noncovalent bonds.

The AI ECD mass spectra shown in Figure $4 b, d$, and $\mathrm{f}$, give further credence to the hypothesis that the nitrotyrosine acts as an electron trap and prevents backbone cleavage. As discussed above, if N-C $\alpha$ cleavage was occurring but the fragments were held together by intramolecular hydrogen bonds, then activation should release the fragments by disrupting these noncovalent bonds (post-ECD activation), or allow direct observation of the fragments by unfolding the precursor ion (pre-ECD activation). Both pre-ECD activation (Figure $4 b, d$, and $f$ ) and post-ECD activation (see Supplemental Figure 2) show no significant increase in $c / z$-type fragmentation. Some increase in the relative abundances of $y$ fragments is observed in the AI ECD mass spectra. That observation is likely the result of the increased internal energy of the peptide ions.

To further investigate the hypothesis that the ammonia is lost from a protonated lysine side-chain, which is interacting with the nitro-group, we performed ECD on series of peptides $A_{x} n Y A_{y} K$, where $x, y=0-6$, and $(x+$ $y)=6$. The dependence of the position of the nitrotyrosine with respect to the protonated lysine on the loss of ammonia and other neutral species is shown in Figure 5. The ECD mass spectra of these peptides and doubly-charged AAAAAAAK are shown in Supplemental Figure 3. Previous work in our laboratory has suggested that the ECD behavior of polyalanine species is nonstandard. The dominant fragmentation channels involve $b / y$-type cleavage (see Supplemental Figure $3 h)$, i.e., do not proceed via the Cornell and/or UW mechanism. That behavior was also observed by Tsybin and coworkers [47] and is seen here for the $A_{x} n Y A_{y} K$ peptides. We postulate that the atypical behavior is likely a consequence of the secondary structure of these peptides [48] but that hypothesis requires further investigation and is beyond the scope of the present paper. The important point in the present context is that the peaks corresponding to neutral losses involving ammonia show marked increases in relative abundance as the proximity of the nitrotyrosine and lysine residues increases, in contrast with those observed for $\bullet \mathrm{OH}$ and $\left[\bullet \mathrm{OH}+\mathrm{H}_{2} \mathrm{O}\right]$. No ammonia loss was observed when there are greater than four amino acids between the two functional species. Once the nitrotyrosine is within this four amino acid threshold for these peptides there is a major loss of ammonia and the $\left[\bullet \mathrm{OH}+\mathrm{H}_{2} \mathrm{O}+\mathrm{NH}_{3}\right]$ neutral losses become the most abundant.

\section{Effect of Charge-State on ECD Behavior of Nitrated Peptides}

As mentioned above, the ECD mass spectra of the triply-charged ions of peptides GPLEnYGFAKGPLAK and nYLEFISDAIIHVLHSK show neutral losses; however they also reveal far greater peptide sequence coverage than for their doubly-charged counterparts, Figure 2. Possibly, the differences observed between the ECD of doubly- and triply-charged nitrated peptides is simply the result of the repulsion between the dissociating fragments. However, AI ECD of the doublycharged peptides did not result in a significant increase in the number or relative abundance of sequence fragments (see above). 
$[\mathrm{GPLEnYGFAK}+2 \mathrm{H}]^{2+}$

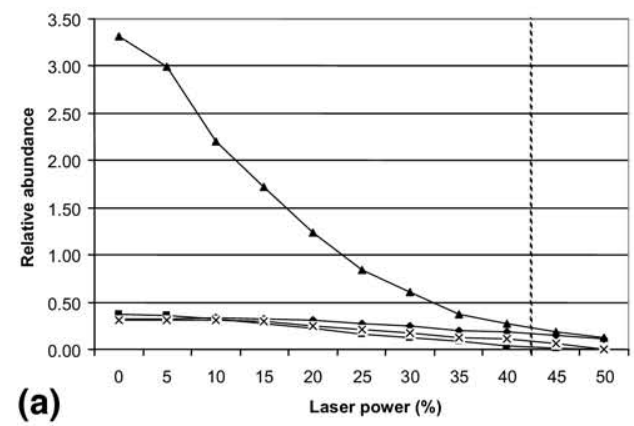

(a)

[GPLEnYGFAKGPLAK+3H] $]^{3+}$

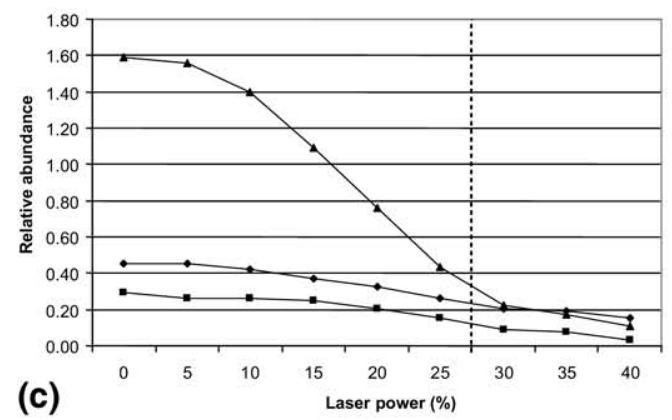

(c)

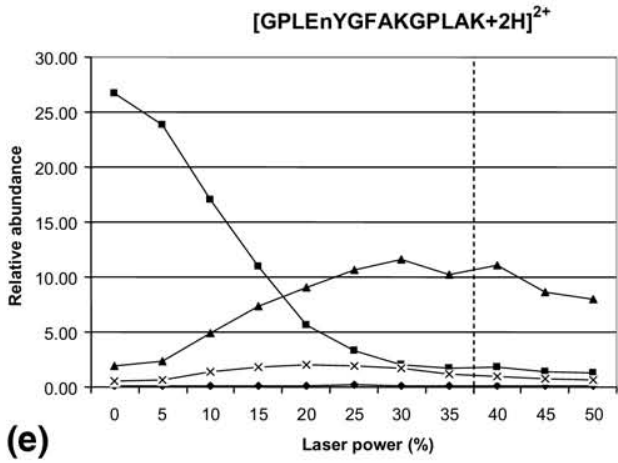

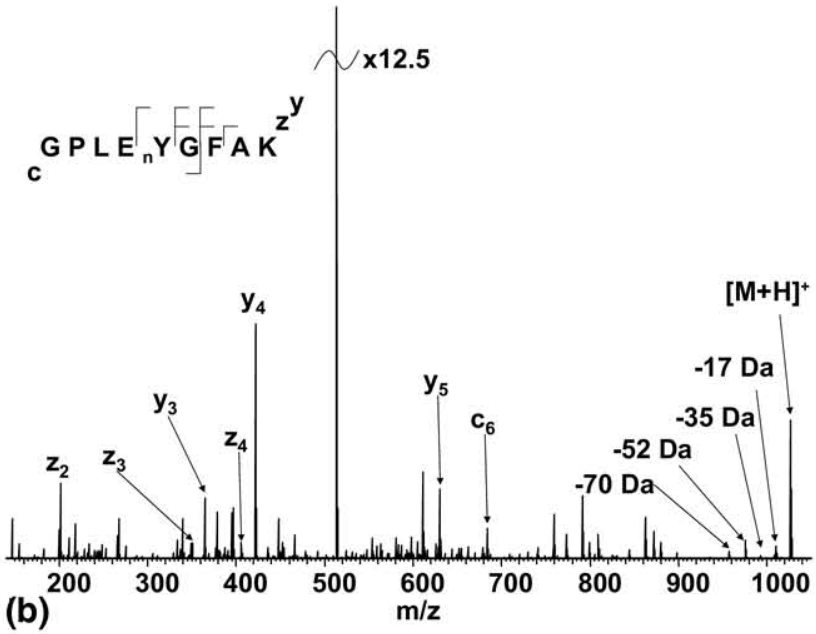

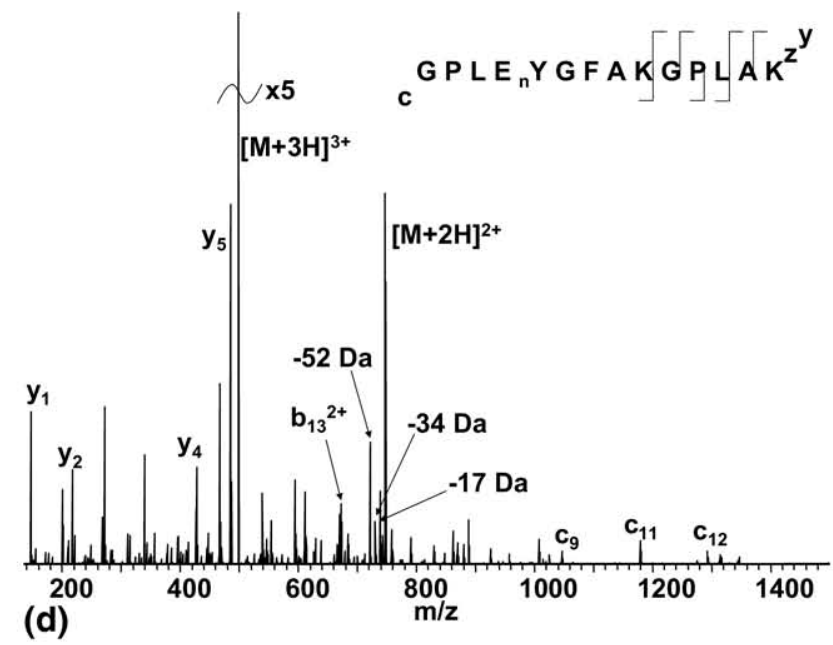

$\rightarrow-\mathrm{OH}^{-}$

$\mathrm{NH}_{3}$ $+\cdot \mathrm{OH} \mathrm{H}_{2} \mathrm{ONH}_{3}$ $-\times-\cdot \mathrm{OH} \mathrm{H}_{2} \mathrm{O} \mathrm{NH}_{3} \mathrm{H}_{2} \mathrm{O}$

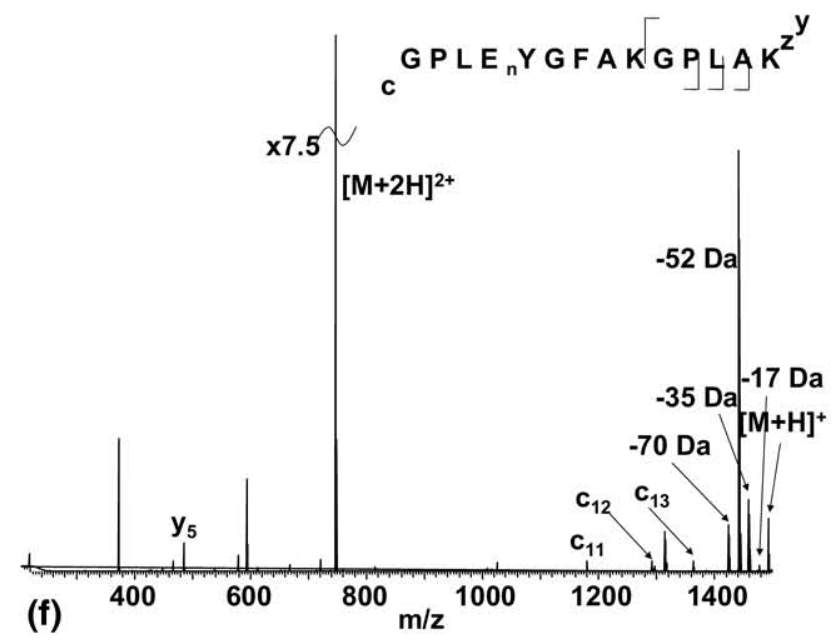

Figure 4. Effect of increasing pre-ECD infrared irradiation on the intensities of neutral loss peaks (normalized to the charge-reduced species) together with the near-threshold AI ECD mass spectra from: (a) and (b) [GPLEnYGFAK $+2 \mathrm{H}]^{2+}$, (c) and (d) [GPLEnYGFAKGPLAK $\left.+3 \mathrm{H}\right]^{3+}$, and (e) and (f) [GPLEnYGFAKGPLAK $+2 \mathrm{H}]^{2+}$ precursor ions. The dashed vertical line shows the threshold for IRMPD of the peptide.

Three possibilities exist to explain the behavior of the triply-charged nitrated peptides. First, the electron predator model does not apply to these species and the peptides fragment according to either the Cornell or UW mechanism. Second, there exists a competition between the electron predator model and the Cornell 


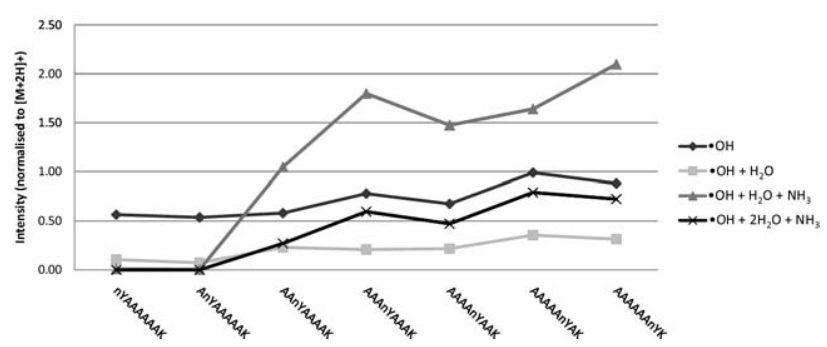

Figure 5. Effect of nitrotyrosine position on the abundance of neutral losses (normalized to the charge-reduced species) following ECD of the peptide series $A_{x} n Y A_{y} K$.

and/or UW mechanism. Finally, the observations may be the result of secondary electron capture, i.e., capture of the first electron proceeds via the electron predator model and capture of the second electron proceeds via the Cornell and/or UW mechanism resulting in c/z-type cleavage.

There are two key observations: All of the sequence fragments observed for the triply-charged precursors are singly-charged, with the exception of $c_{15}{ }^{2+}$ ions from ECD of [nYLEFISDAIIHVLHSK $+3 \mathrm{H}]^{3+}$ ions. For both peptides, no fragments are observed in the vicinity of the nitrotyrosine residue and those that are observed derive from the $\mathrm{C}$-terminal region. The ECD mass spectrum of unmodified triply-charged GPLEYGFAKGPLAK is shown in Supplementary Figure 4. (Unmodified triplycharged YLEFISDAIIHVLHSK was not observed in the myoglobin digest and hence the results are not available for comparison). All possible $\mathrm{N}-\mathrm{C} \alpha$ cleavages of GPLEYGFAKGPLAK were observed. In addition, doubly-charged fragments $c_{13}{ }^{2+}, z_{12}{ }^{2+}$, and $z_{11}{ }^{2+}$ were observed. Clearly, the presence of the nitrotyrosine inhibits $c / z$-type cleavage within the triply-charged species in a manner comparable to that observed for doubly-charged peptides. The conclusion drawn is that there does exist a competition between the electron predator model and $c / z$-type fragmentation. The question remains: Is that competition biased such that the electron predator model prevails over $c / z$-type fragmentation, i.e., are all $c / z$ fragments the result of secondary electron capture? The lack of doubly-charged fragments from GPLEnYGFAKGPLAK and the presence of doublycharged fragments from GPLEYGFAKGPLAK suggest that may be the case. It should be noted that the relative abundance of the doubly-charged fragments in the modified species is low and that a lack of doublycharged fragments is not uncommon in the ECD of triply-charged fragments (for example, see [49]. Moreover, triply-charged nYLEFISDAIIHVLHSK yields $c_{15}{ }^{2+}$ fragments, which are clearly the result of single electron capture and the Cornell and/or UW mechanism.

The fact that no fragments are observed in the vicinity of the nitrotyrosine residue for either peptide suggests that the conformation of the peptide ions is important. As described above, the probable protonation sites for triply-charged GPLEnYGFAKGPLAK are the Nterminus and the two lysine side-chains, and for triply- charged nYLEFISDAIIHVLHSK they are the N-terminus, the lysine side-chain, and the side-chain of one of the histidine residues. Hence, the triply-charged species are predicted to have more extended conformations than their doubly-charged counterparts. Through-bond electrontransfer rates have been shown to be dependent on distance [50]. Therefore, the current observations could be explained as follows: If electron capture to a high- $n$ Rydberg state of the central lysine (GPLEnYGFAKGPLAK) or histidine (nYLEFISDAIIHVLHSK) occurs, the nitrotyrosine intercepts and traps the electron, whereas if the electron is captured to a high- $n$ Rydberg state of the C-terminal lysine (both peptides), relaxation to the amide $\pi^{*}$ orbital proceeds with subsequent $\mathrm{N}-\mathrm{C} \alpha$ cleavage. It might be expected that if the UW mechanism prevails, $c / z$-type fragmentation throughout the peptide, and not simply in the region of the protonation site, would be observed; however it is a requirement of the mechanism that the conformation necessary for proton abstraction be achieved and that may not be possible for the species studied here.

We suggest that providing the peptide is of sufficient length and the charge of the precursor is $>N+2$, where $N=$ number of nitrotyrosines, ECD of nitrated peptides and proteins should produce backbone fragments [51].

\section{Conclusion}

In terms of sequencing and characterization of sites of modification, our results show that ECD is not the method of choice for doubly-charged nitrotyrosinecontaining peptide ions. Some sequence information can be gleaned following ECD of triply-charged precursor ions. CID behavior is unaffected by the presence of tyrosine nitration. ECD of nitrated peptides is characterized by loss of small neutrals including $\bullet \mathrm{OH}$, water, and ammonia. Losses involving ammonia in isolation were not observed. It is hypothesized that these losses arise through interactions between protonated lysine side-chains and the nitro group, and corroborating evidence for this theory is provided by activated ion ECD, isotopically labeled ${ }^{15} \mathrm{NO}_{2}$-tyrosine, and a peptide series with variable nitrotyrosine sites.

\section{Acknowledgments}

The authors acknowledge EPSRC (A.W.J. and H.J.C.), Ramon y Cajal Programme (CTQ2006-14,959) and Ministerio de Ciencia y tecnologia (CTQ2007-62,345), Spain (J.I.), and the Wellcome Trust (074131 and 080998) (H.J.C. and V.A.M., respectively) for funding.

\section{Appendix A Supplementary Material}

Supplementary material associated with this article may be found in the online version at doi:10.1016/ j.jasms.2009.10.011. 


\section{References}

1. Abello, N.; Kerstjens, H. A. M.; Postma, D. S.; Bischoff, R. Protein Tyrosine Nitration: Selectivity, Physicochemical, and Biological Consequences, Denitration, and Proteomics Methods for the Identification of Tyrosine Nitrated Proteins. J. Proteome Res. 2009, 8(7), 3222-3238.

2. Beckman, J. S. Oxidative Damage and Tyrosine Nitration from Peroxynitrite. Chem. Res. Toxicol. 1996, 9(5), 836-844.

3. Reiter, C. D.; Teng, R. J.; Beckman, J. S. Superoxide Reacts with Nitric Oxide to Nitrate Tyrosine at Physiological pH Via Peroxynitrite. J. Biol. Chem. 275, 42, 32460-32466.

4. Radi, R. Nitric Oxide, Oxidants, and Protein Tyrosine Nitration. Proc. Nat. Acad. Sci. USA 2004, 10(12), 4003-4008.

5. Ischiropoulos, H. Biological Tyrosine nitration: A Pathophysiological Function of Nitric Oxide and Reactive Oxygen Species. Arch. Biochem. Biophys. 1998, 356(1), 1-11.

6. Ischiropoulos, H.; Almehdi, A. B. Peroxynitrite-Mediated Oxidative Protein Modifications. FEBS Lett. 1995, 364(3), 279-282.

7. Shishehbor, M. H.; Aviles, R. J.; Brennan, M. L.; Fu, X. M.; Goormastic, M.; Pearce, G. L.; Gokce, N.; Keaney, J. F.; Penn, M. S.; Sprecher, D. L.; Vita, J. A.; Hazen, S. L. Association of Nitrotyrosine Levels with Cardiovascular Disease and Modulation by Statin Therapy. JAMA 2003, 289(13), 1675-1680.

8. Good, F.; Werner, P.; Hsu, A.; Olanow, C. W.; Perl, D. P. Evidence for Neuronal Oxidative Damage in Alzheimer's Fisease. Am. J. Pathol. 1996, 149(1), 21-28.

9. Parastatidis, I.; Thomson, L.; Burke, A.; Chernysh, I.; Nagaswami, C.; Visser, J.; Stamer, S.; Liebler, D. C.; Koliakos, G.; Heijnen, H. F. G.; FitzGerald, G. A.; Weisel, J. W.; Ischiropoulos, H. Fibrinogen $\beta$-Chain Tyrosine Nitration Is a Prothrombotic Risk Factor. J. Biol. Chem. 283, 49, 33846-33853.

10. Zubarev, R. A.; Kelleher, N. L.; McLafferty, F. W. Electron Capture Dissociation of Multiply Charged Protein Cations. A nonergodic process. J. Am. Chem. Soc. 1998, 120(13), 3265-3266.

11. Cooper, H. J.; Hakansson, K.; Marshall, A. G. The Role of Electron Capture Dissociation in Biomolecular Analysis. Mass Spectrom. Rev. 2005, 24, 201-222.

12. McLuckey, S. A.; Goeringer, D. E. Slow Heating Methods in Tandem Mass Spectrometry. J. Mass Spectrom. 1997, 3(5), 461-474.

13. Little, D. P.; Speir, J. P.; Senko, M. W.; O'Connor, B.; McLafferty, F. W. Infrared Multiphoton Dissociation of Large Multiply-Charged Ions for Biomolecule Sequencing. Anal. Chem. 1994, 66(18), 2809-2815.

14. Woodin, R. L.; Bomse, D. S.; Beauchamp, J. L. Multi-Photon Dissociation of Molecules with Low-Power Continuous Wave Infrared-Laser Radiation. J. Am. Chem. Soc. 1978, 100(10), 3248-3250.

15. Kruger, N. A.; Zubarev, R. A.; Carpenter, B. K.; Kelleher, N. L.; Horn, D. M.; McLafferty, F.W. Electron Capture Versus Energetic Dissociation of Protein Ions. Int. J. Mass Spectrom. 1999, 182, 1-5

16. Savitski, M. M.; Kjeldsen, F.; Nielsen, M. L.; Zubarev, R. A. Hydrogen Rearrangement to and from Radical z Fragments in Electron Capture Dissociation of Peptides. J. Am. Soc. Mass Spectrom. 2007, 18(1), 113-120.

17. Zubarev, R. A.; Haselmann, K. F.; Budnik, B.; Kjeldsen, F.; Jensen, F. Towards an Understanding of the Mechanism of Electron-Capture Dissociation: A Historical Perspective and Modern Ideas. Eur. J. Mass Spectrom. 2002, 8(5), 337-349.

18. Roepstorff, P.; Fohlman, J. Proposal for a Common Nomenclature for Sequence Ions in Mass-Spectra of Peptides. Biomed. Mass Spectrom. 1984, $11(11), 601$.

19. Leymarie, N.; Costello, C. E.; O'Connor, P. B. Electron Capture Dissociation Initiates a Free Radical Reaction Cascade. J. Am. Chem. Soc. 2003, 12(29), 8949-8958.

20. Syrstad, E. A.; Turecek, F. Toward a General Mechanism of Electron Capture Dissociation. J. Am. Soc. Mass Spectrom. 2005, 16(2), 208-224.

21. Chen, X.; Turecek, F. The Arginine Anomaly: Arginine Radicals are Poor Hydrogen Donors in Electron Transfer Induced Dissociations. J. Am. Chem. Soc. 2006, 128, 12520-12530.

22. Sobczyk, M.; Anusiewicz, W.; Berdys-Kochanska, J.; Sawicka, A.; Skurski, P.; Simons, J. Coulomb-Assisted Dissociative Electron Attachment: Application to a Model Peptide. J. Phys. Chem. A 2005, 109, 250-258.

23. Cooper, H. J.; Hudgins, R. R.; Hakansson, K.; Marshall, A. G. Secondary Fragmentation of Linear Peptides in Electron Capture Dissociation. Int. J. Mass Spectrom. 2003, 228(2/3), 723-728.

24. Zubarev, R. A.; Horn, D. M.; Fridriksson, E. K.; Kelleher, N. L.; Kruger, N. A.; Lewis, M. A.; Carpenter, B. K.; McLafferty, F. W. Electron Capture Dissociation for Structural Characterization of Multiply Charged Protein Cations. Anal. Chem. 2000, 72(3), 563-573.

25. Axelsson, J.; Palmblad, M.; Hakansson, K.; Hakansson, P. Electron Capture Dissociation of Substance P Using a Commercially Available Fourier Transform Ion Cyclotron Resonance Mass Spectrometer. Rapid Commun. Mass Spectrom. 1999, 13(6), 474-477.

26. Kelleher, R. L.; Zubarev, R. A.; Bush, K.; Furie, B.; Furie, B. C.; McLafferty, F. W.; Walsh, C. T. Localization of Labile Post-Translational Modifications by Electron Capture Dissociation: The Case of $\boldsymbol{\gamma}$ Carboxyglutamic Acid. Anal. Chem. 1999, 71(19), 4250-4253.

27. Hakansson, K.; Cooper, H. J.; Emmett, M. R.; Costello, C. E.; Marshall, A. G.; Nilsson, C. L. Electron Capture Dissociation and Infrared
Multiphoton Dissociation MS/MS of an N-Glycosylated Tryptic Peptide to Yield Complementary Sequence Information. Anal. Chem. 2001, 73(18), 4530-4536.

28. Mirgorodskaya, E.; Roepstorff, P.; Zubarev, R. A. Localization of O-Glycosylation Sites in Peptides by Electron Capture Dissociation in a Fourier Transform Mass Spectrometer. Anal. Chem. 1999, 71(20), 44314436.

29. Shi, S. D. H.; Hemling, M. E.; Carr, S. A.; Horn, D. M.; Lindh, I.; McLafferty, F. W. Phosphopeptide/Phosphoprotein Mapping by Electron Capture Dissociation Mass Spectrometry. Anal. Chem. 2001, 73(1), 19-22.

30. Stensballe, A.; Jensen, O. N.; Olsen, J. V.; Haselmann, K. F.; Zubarev, R. A. Electron Capture Dissociation of Singly and Multiply Phosphorylated Peptides. Rapid Commun. Mass Spectrom. 2000, 14(19), 1793-1800.

31. Guan, Z. Q. Identification and Localization of the Fatty Acid Modification in Ghrelin by Electron Capture Dissociation. J. Am. Soc Mass Spectrom. 2002, 13(12), 1443-1447.

32. Guan, Z. Q.; Yates, N. A.; Bakhtiar, R. Detection and Characterization of Methionine Oxidation in Peptides by Collision-Induced Dissociation and Electron Capture Dissociation. J. Am. Soc. Mass Spectrom. 2003, 14(6), 605-613.

33. Cooper, H. J.; Heath, J. K.; Jaffray, E.; Hay, R. T.; Lam, T. T.; Marshall, A. G. Identification of Sites of Ubiquitination in Proteins: A Fourier Transform Ion Cyclotron Resonance Mass Spectrometry Approach. Anal. Chem. 2004, 76, 6982-6988.

34. Cooper, H. J.; Tatham, M. H.; Jaffray, E.; Heath, J. K.; Lam, T. T Marshall, A. G.; Hay, R. T. FT-ICR Mass Spectrometry for the Analysis of SUMO Modification: Identification of Lysines in RanBP2 and SUMO Targeted for Modification During the E3 AutoSUMOylation reaction. Anal. Chem. 2005, 77, 6310-6319.

35. Creese, A. J.; Cooper, H. J. The Effect of Phosphorylation on the Electron Capture Dissociation of Peptide Ions. J. Am. Soc. Mass Spectrom. 2008, 19 $1263-1274$.

36. Sohn, C. H.; Chung, C. K.; Yin, S.; Ramachandran, P.; Loo, J. A. Beauchamp, J. L. Probing the Mechanism of Electron Capture and Electron Transfer Dissociation Using Tags with Variable Electron Affinity. J. Am. Chem. Soc. 2009, 131(15), 5444-5459.

37. Desfrancois, C.; Periquet, V.; Lyapustina, S. A.; Lippa, T. P.; Robinson D. W.; Bowen, K. H.; Nonaka, H.; Compton, R. N. Electron Binding to Valence and Multipole States of Molecules: Nitrobenzene, Para- and Meta-Dinitrobenzenes. I. Chem. Phys. 1999, 111(10), 4569-4576.

38. Fukuda, E. K.; McIver, R. T. Relative Electron Affinities of Substituted Benzophenones, Nitrobenzenes, and Quinones. J. Am. Chem. Soc. 1985, 107, 2291-2296.

39. Horn, D. M.; Ge, Y.; McLafferty, F. W. Activated Ion Electron Capture Dissociation for Mass Spectral Sequencing of Larger (42 kDa) Proteins. Anal. Chem. 2000, 73, 4778-4784.

40. Kendall, G.; Cooper, H. J.; Heptinstall, J.; Derrick, J.; Walton, D. J. Peterson, I. R. Specific Electrochemical Nitration of Horse Heart Myoglobin. Arch. Biochem. Biophys. 2001, 392(2), 169-179.

41. Mikhailov, V. A.; Cooper, H. J. Activated Ion Electron Capture Dissociation (AI ECD) of Proteins: Synchronization of Infrared and Electron Irradiation with Ion Magnetron Motion. J. Am. Soc. Mass Spectrom. 2009, 20(5), 763-771.

42. Chalkley, R. J.; Baker, R.; Medzihradszky, K. F.; Lynn, A. J.; Burlingame, A. L. In-Depth Analysis of Tandem Mass Spectrometry Data from Disparate Instrument Types. Mol. Cell. Proteom. 2008, 7(12), 2386-2398.

43. Breuker, K.; Oh, H.; Cerda, B.; Horn, D. M.; McLafferty, F. W. Hydrogen Atom Loss in ECD: A Fourier Transform Ion Cyclotron Resonance Study with Single Isotopomeric Ions. Eur. J. Mass Spectrom. 2002, 8 , 177-180.

44. Polasek, M.; Turecek, F. Hydrogen Atom Adducts to Nitrobenzene: Formation of the Phenylnitronic Radical in the Gas Phase and Energetics of Wheland Intermediates. J. Am. Chem. Soc. 2000, 122(39), 9511-9524.

45. Sokolovsky, M.; Riordan, J. F.; Vallee, B. L. Conversion of 3-Nitrotyrosine to 3-Aminotyrosine in Peptides and Proteins. Biochem. Biophys. Res. Commun. 1967, 27(1), 20-25.

46. De Filippis, V.; Frasson, R.; Fontana, A. 3-Nitrotyrosine as a Spectroscopic Probe for Investigating Protein-Protein Interactions. Protein Sci. 2006, 15(5), 976-986.

47. Hamidane, H. B.; Chiappe, D.; Hartmer, R.; Vorobyev, A.; Moniatte, M.; Tsybin, Y. O. Electron Capture and Transfer Dissociation: Peptide Structure Analysis at Different Ion Internal Energy Levels. J. Am. Soc. Mass Spectrom. 2009, 20, 567-575.

48. Hudgins, R. R.; Ratner, M. A.; Jarrold, M. F. Design of Helices that are Stable In Vacuo. J. Am. Chem. Soc. 1998, 120, 12974-12975.

49. Hamidane, H. B.; He, H.; Tsybin, O. Y.; Emmett, M. R.; Hendrickson, C. L.; Marshall, A. G.; Tsybin, Y. O. Periodic Sequence Distribution of Product Ion Abundances in Electron Capture Dissociation of Amphipathic Peptides and Proteins. J. Am. Soc. Mass Spectrom. 2009, 20 1182-1192.

50. Sobczyk, M.; Simons, J. Distance Dependence of Through-Bond Electron Transfer Rates in Electron-Capture and Electron-Transfer Dissociation. Int. J. Mass Spectrom. 2006, 253, 274-280.

51. Mikhailov, V. A.; Iniesta, J.; Jones, A. W.; Cooper, H. J. unpublished (manuscript in preparation). 